\title{
A better treatment for saphenous vein graft disease after coronary artery bypass surgery: Might statins be the answer at the right dose to the right patient at the right time?
}

\author{
Cesario F. Bianchi, MD, PhD, FAHA, ${ }^{\mathrm{a}}$ and Orlando Petrucci, $\mathrm{MD}, \mathrm{PhD}^{\mathrm{b}}$
}

\footnotetext{
From the ${ }^{a}$ Technological and Biotechnological Research Centers, School of Medicine, University of Mogi das Cruzes, Mogi das Cruzes, São Paulo, Brazil; and the ${ }^{\mathrm{b}}$ Department of Surgery, Faculty of Medical Science, State University of Campinas, Campinas, São Paulo, Brazil.

Disclosures: Authors have nothing to disclose with regard to commercial support.

Received for publication July 1, 2018; revisions received July 1, 2018; accepted for publication July 2, 2018; available ahead of print Aug 10, 2018.

Address for reprints: Cesario F. Bianchi, MD, PhD, FAHA, Technological and Biotechnological Research Centers, School of Medicine, University of Mogi das Cruzes, Av Dr Candido Xavier de Almeida, CEP: 08780-911 Mogi das Cruzes, SP, Brazil (E-mail: cesariobianchi@gmail.com).

J Thorac Cardiovasc Surg 2019;157:162-3 $0022-5223 / \$ 36.00$

Copyright (C) 2018 by The American Association for Thoracic Surgery https://doi.org/10.1016/j.jtcvs.2018.07.003
}

Surgical methods to harvest and graft veins into coronary arteries are well optimized so pharmacologic interventions are often explored as the next step to maintain saphenous vein graft (SVG) patency. Aspirin and statin drugs are actual pharmacologic treatments for SVG disease.

Statins became a multipurpose drug because of their pleiotropic effects beyond cholesterol lowering. ${ }^{2}$ Statins at the optimal dose to the right patient and at the appropriate time may be the answer for surgeons frustrated with SVG disease progression despite tireless efforts to optimize surgical revascularization procedures.

SVG disease pathophysiology has 3 main phases: early thrombosis (up to 30 days) followed by smooth muscle hyperplasia (up to 1 year) and atherosclerosis (after 1 year).

Ideally, one would want to delay the disease development at the earliest point and consequently avoid SVG stenosis and failure. Because statins are already used successfully to treat hypercholesterolemia and long-term SVG disease, it is reasonable to test these agents short term with higher doses. Kulik and colleagues did just that. ${ }^{3}$

A well-designed pilot trial comparing the effects of atorvastatin (intense [80 mg/day] and moderate [10 mg/day] doses) on early graft occlusion of 173 patients who underwent SVG for coronary artery bypass surgery. The moderate dose was not better than the intense dose according to computed $P$ values with an $\alpha$ set at 0.05 . If more broadly aimed at SVG disease, including either occlusion or stenosis, better response was recorded, albeit not yet significant.

\section{RIGHT DOSE}

When we analyze experiments with negative results, it is essential to make sure that the drug was effective. Low-density lipoprotein levels clearly showed a highly

\section{RIGHT PATIENT}

\section{RIGHT TIME}

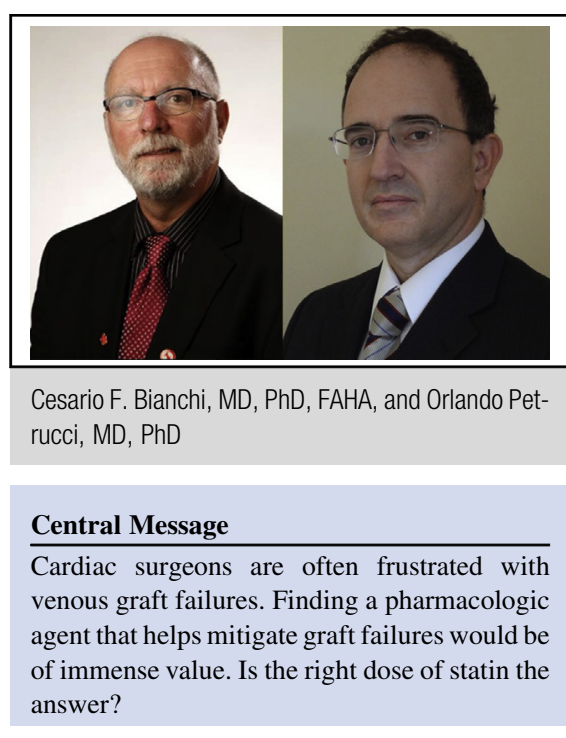

See Article page 151

significant decrease between moderate and intense doses, reassuring that, for what statins are better known for, the different doses are acting accordingly. It also may mean that plasma low-density lipoprotein levels below a certain level has marginal, if any, influence on the development of SVG disease at 1 year.

The closest statistically significant result was, unfortunately, elevated liver enzymes in 3 patients in the intense treatment group compared with none in the moderate group. Treatment discontinuation, however, was due to patient preferences (side effects) or physician insistence on open label treatment. The pharmacogenomic properties of statins may guide to a personalized medicines with fewer risks and more efficiency. ${ }^{4-6}$

If the pathophysiology of SVG disease is correct, statins are effective at the late atherosclerotic phase. In the earlier phases (ie, thrombosis and/or smooth muscle hyperplasia), other pharmacologic agents are likely better candidates. A good response to long-term prevention of SVG disease 
using statins ${ }^{7}$ and other lipid-lowering $\operatorname{drugs}^{8}$ has been documented.

\section{RIGHT TRIAL}

The authors should be congratulated for their efforts at bringing trustworthy negative data to such an important medical problem.

The publication of well-controlled negative results is important because it helps to prepare more realistic evidence-based systematic review ${ }^{9,10}$ to guide medical treatments.

As we keep learning from well-controlled negative clinical studies, the next trials will have improved chances to yield more efficacious treatments for important medical problems.

\section{References}

1. Kim FY, Marhefka G, Ruggiero NJ, Adams S, Whellan DJ. Saphenous vein graft disease: review of pathophysiology, prevention, and treatment. Cardiol Rev. 2013;21:101-9.

2. Jerzewski K, Ruel M, Voisine P, Le May MR, Kulik A. Does high-density lipoprotein influence the development of saphenous vein graft disease after coronary bypass surgery?: exploratory analysis from the CASCADE trial. J Cardiothorac Surg. 2013;8:172

3. Kulik A, Abreu AM, Boronat V, Ruel M. Intensive versus moderate statin therapy and early graft occlusion after coronary bypass surgery: the Aggressive Cholesterol Therapy to Inhibit Vein Graft Events randomized clinical trial. J Thorac Cardiovasc Surg. 2019;157:151-61.e1.

4. Bellosta S, Corsini A. Statin drug interactions and related adverse reactions: an update. Expert Opin Drug Safe. 2018;17:25-37.

5. Mitchell D, Guertin JR, Iliza AC, Fanton-Aita F, LeLorier J. Economic evaluation of a pharmacogenomics test for statin-induced myopathy in cardiovascular high-risk patients initiating a statin. Molec Tiagnosis Ther. 2017;21:95-105.

6. Maxwell WD, Ramsey LB, Johnson SG, Moore KG, Shtutman M, Schoonover JH, et al. Impact of pharmacogenetics on efficacy and safety of statin therapy for dyslipidemia. Pharmacotherapy. 2017;37:1172-90.

7. Knatterud GL, Rosenberg Y, Campeau L, Geller NL, Hunninghake DB, Forman SA, et al. Long-term effects on clinical outcomes of aggressive lowering of low-density lipoprotein cholesterol levels and low-dose anticoagulation in the post coronary artery bypass graft trial. Post CABG Investigators. Circulation. 2000; 102:157-65.

8. Post Coronary Artery Bypass Investigators. The effect of aggressive lowering of low-density lipoprotein cholesterol levels and low-dose anticoagulation on obstructive changes in saphenous-vein coronary-artery bypass grafts. $N$ Engl J Med. 1997;336:153-62.

9. Ioannidis JP. Effectiveness of antidepressants: an evidence myth constructed from a thousand randomized trials? Philosophy Ethics Humanities Med. 2008; $3: 14$.

10. Moller MH, Ioannidis JPA, Darmon M. Are systematic reviews and metaanalyses still useful research? We are not sure. Intensive Care Med. 2018;44 518-20. 